\title{
Cigarette smoking and outcomes after aneurysmal subarachnoid hemorrhage: a nationwide analysis
}

\author{
Hormuzdiyar H. Dasenbrock, MD, MPH, Robert F. Rudy, BS, Pui Man Rosalind Lai, MD, \\ Timothy R. Smith, MD, PhD, MPH, Kai U. Frerichs, MD, William B. Gormley, MD, MPH, MBA, \\ M. Ali Aziz-Sultan, MD, and Rose Du, MD, PhD \\ Cushing Neurosurgery Outcomes Center, Department of Neurosurgery, Brigham and Women's Hospital, Harvard Medical \\ School, Boston, Massachusetts
}

\begin{abstract}
OBJECTIVE Although cigarette smoking is one of the strongest risk factors for cerebral aneurysm development and rupture, there are limited data evaluating the impact of smoking on outcomes after aneurysmal subarachnoid hemorrhage (SAH). Additionally, two recent studies suggested that nicotine replacement therapy was associated with improved neurological outcomes among smokers who had sustained an SAH compared with smokers who did not receive nicotine.
\end{abstract}

METHODS Patients who underwent endovascular or microsurgical repair of a ruptured cerebral aneurysm were extracted from the Nationwide Inpatient Sample (NIS, 2009-2011) and stratified by cigarette smoking. Multivariable logistic regression analyzed in-hospital mortality, complications, tracheostomy or gastrostomy placement, and discharge to institutional care (a nursing or an extended care facility). Additionally, the composite NIS-SAH outcome measure (based on mortality, tracheostomy or gastrostomy, and discharge disposition) was evaluated, which has been shown to have excellent agreement with a modified Rankin Scale score greater than 3. Covariates included in regression constructs were patient age, sex, race/ethnicity, insurance status, socioeconomic status, comorbidities (including hypertension, drug and alcohol abuse), the NIS-SAH severity scale (previously validated against the Hunt and Hess grade), treatment modality used for aneurysm repair, and hospital characteristics. A sensitivity analysis was performed matching smokers to nonsmokers on age, sex, number of comorbidities, and NIS-SAH severity scale score.

RESULTS Among the 5784 admissions evaluated, $37.1 \%(n=2148)$ had a diagnosis of tobacco use, of which $31.1 \%$ ( $n$ $=1800)$ were current and $6.0 \%(n=348)$ prior tobacco users. Smokers were significantly younger (mean age 51.4 vs 56.2 years) and had more comorbidities compared with nonsmokers $(p<0.001)$. There were no significant differences in mortality, total complications, or neurological complications by smoking status. However, compared with nonsmokers, smokers had significantly decreased adjusted odds of tracheostomy or gastrostomy placement (11.9\% vs $22.7 \%$, odds ratio [OR] $0.63,95 \%$ confidence interval $[\mathrm{Cl}] 0.51-0.78, \mathrm{p}<0.001)$, discharge to institutional care $(\mathrm{OR} 0.71,95 \% \mathrm{Cl}$ $0.57-0.89, p=0.002$ ), and a poor outcome (OR 0.65, 95\% Cl 0.55-0.77, p<0.001). Similar statistical associations were noted in the matched-pairs sensitivity analysis and in a subgroup of poor-grade patients (the upper quartile of the NISSAH severity scale).

CONCLUSIONS In this nationwide study, smokers experienced SAH at a younger age and had a greater number of comorbidities compared with nonsmokers, highlighting the negative ramifications of cigarette smoking among patients with cerebral aneurysms. However, smoking was also associated with paradoxical superior outcomes on some measures, and future research to confirm and further understand the basis of this relationship is needed.

https://thejns.org/doi/abs/10.3171/2016.10.JNS16748

KEY WORDS cerebral aneurysm; Nationwide Inpatient Sample; nicotine; outcomes; smoking; subarachnoid hemorrhage; tobacco; vascular disorders

ABBREVIATIONS ASA = American Society of Anesthesiologists; $\mathrm{Cl}=$ confidence interval; $\mathrm{COPD}=$ chronic obstructive pulmonary disease; GOS = Glasgow Outcome Scale; NIS = Nationwide Inpatient Sample; NSQIP = National Surgical Quality Improvement Program; OR = odds ratio; SAH = subarachnoid hemorrhage.

ACCOMPANYING EDITORIAL See pp 442-445. DOI: 10.3171/2016.12.JNS162628.

SUBMITTED March 23, 2016. ACCEPTED October 14, 2016.

INCLUDE WHEN CITING Published online October 27, 2017; DOI: 10.3171/2016.10.JNS16748. 


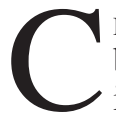
IGARETTE smoking is one of the most detrimental behaviors to health, and an estimated $18 \%$ of deaths in the US are attributable to smoking. ${ }^{16}$ Among the many negative consequences of cigarette smoking include that it is a well-known risk factor for the development and rupture of cerebral aneurysms. ${ }^{4,9,17,21,22,33,34,36,39,43}$ An estimated $29 \%$ of the attributable risk of aneurysmal subarachnoid hemorrhage (SAH) is due to smoking, and smoking cessation decreases the risk of SAH. ${ }^{21}$ Although cigarette smoking has decreased internationally, approximately $17.8 \%$ of the adult population in the US are current smokers. ${ }^{31}$

While smoking is a potent risk factor for $\mathrm{SAH}$, the impact of smoking on the outcomes following rupture of cerebral aneurysms is poorly understood. Prior studies have found that smokers sustain rupture at a younger age ${ }^{51}$ and have an increased risk of delayed cerebral ischemia. ${ }^{18,29}$, ${ }^{40,51}$ However, analyses of the association of smoking with outcomes after SAH have reported conflicting results. ${ }^{37}$ Notably, two studies suggested that nicotine replacement therapy in smokers who sustained aneurysmal SAH was associated with superior outcomes, ${ }^{12,45}$ and this observation has been hypothesized to potentially be attributable to neuroprotective properties of nicotine.

Given the prevalence of smoking, additional data evaluating the association of smoking with outcomes following $\mathrm{SAH}$ are needed, which may inform the treatment of ruptured aneurysms. In this study, a national administrative claims database, the Nationwide Inpatient Sample (NIS; Healthcare Cost and Utilization Project, Agency for Healthcare Research and Quality), and a prospective registry, the National Surgical Quality Improvement Program (NSQIP), were queried to evaluate the association between smoking and outcomes after SAH. It was hypothesized that due to increased odds of delayed cerebral ischemia, smoking would be associated with higher odds of mortality and poor outcomes.

\section{Methods \\ Data Source}

The NIS was queried from the years 2009-2011. The NIS is the largest all-payer administrative database in the US, is a $20 \%$ sample of nonfederal hospitals, and has been extensively used to evaluate the outcomes of patients with SAH. ${ }^{5-8,10,11,14,15,20,25-28,30,35,38,41,42,47-50}$ The year 2009 was the first year included as this was the first year that there were more encoded diagnosis codes (from 15 to 25) for each patient; in 2012, new survey weights were introduced that prohibit variance calculations using combined populations before and after the redesign. Our IRB has determined that studies utilizing the NIS are exempt from individual review.

\section{Inclusion and Exclusion Criteria}

Patients were included who 1) had an ICD-9-CM diagnosis of subarachnoid hemorrhage (430) or intracerebral hemorrhage $(431,432.9), 2)$ underwent microsurgical clipping (39.51) or coil embolization (39.72, 39.75, $39.76,39.79$ ) of an intracranial aneurysm, 3) were at least 18 years of age, and 4) had a nonelective admis- sion. Admissions with a diagnosis of a cerebrovascular malformation (747.81) and cerebral arteritis (437.4) or a procedure code of treatment of an arteriovenous malformation surgically (39.53) or by radiosurgery (923.x) were excluded.

\section{Patient Stratification and ICD-9-CM Validation}

Patients were stratified by the ICD-9-CM codes for current (305.1) or a personal history of (V15.82) tobacco use. Prior validation studies of patients treated in an outpatient setting have suggested that the combination of these codes is effective at identifying smoking status. ${ }^{52}$

To validate these ICD-9-CM codes in patients with cerebral aneurysms, those who underwent microsurgical or endovascular cerebral aneurysm repair at our institution between 2009 and 2015 were evaluated. Documented smoking status was compared with recorded ICD-9-CM codes for tobacco use from billing data. This ICD-9-CM code validation was performed after approval from our IRB.

\section{Covariates}

Patient age and sex were extracted. The Elixhauser index, which includes drug and alcohol abuse, was used to evaluate comorbidities. However, neurological deficits, paralysis, and electrolyte complications were not included in the comorbidity score given the potential misclassification with SAH and its associated complications. Comorbidities encoded in fewer than 20 patients were also excluded from the total score. Insurance status, race or ethnicity, and hospital characteristics are encoded in the NIS. Socioeconomic status was measured indirectly as the median household income in the patient's ZIP code.

The NIS-SAH severity scale, ${ }^{50}$ an externally validated scale that has been shown to have strong concordance with Hunt and Hess grade, was used for severity adjustment. The score was calculated using published methodology, using the ICD-9-CM diagnosis codes for coma, hydrocephalus, hemiparesis, aphasia, and cranial nerve deficits, as well as ICD-9-CM procedure codes for CSF diversion and mechanical ventilation. Treatment modality selected for aneurysm repair was included as a covariate to partially account for differences in institutional practice and aneurysm location. Additionally, decompressive craniectomy (01.25) and cerebral edema (348.5) were evaluated to partially adjust for documented elevated intracranial pressure.

\section{Outcomes}

Outcomes evaluated included in-hospital mortality, complications, and length of hospital stay. Total complications included: neurological (seizures 345.xx, stroke 433.x and 434.x, transient cerebral ischemia [used as an approximation for delayed cerebral ischemia] 435.x, and neurological complications after procedure 997.01, 997.09), cardiac (410.xx, 248.xx, 427.5, 785.xx), pulmonary (514.x, 518.xx, 512.x), renal (584.x), gastrointestinal (578.x, 5601, 00845), venous thromboembolic (453.x, 415.x), hematological (285.x and 998.1x, as well as red blood cell transfusion 94.04), sodium abnormalities $(253.5,253.6,276.0$, 
TABLE 1. Demographics of the NIS study population, stratified by cigarette smoking status

\begin{tabular}{|c|c|c|c|c|c|}
\hline Variable & Total Population & Nonsmoker & Former Smoker & Current Smoker & $\mathrm{p}$ Value \\
\hline No. of patients & 5784 & 3636 & 348 & 1800 & \\
\hline Mean age in yrs (SD) & $54.9(13.7)$ & $56.2(14.6)$ & $58.8(13.2)$ & $51.4(11.2)$ & $<0.001$ \\
\hline Female sex & 68.4 & 71.6 & 62.4 & 63.0 & $<0.001$ \\
\hline \multicolumn{5}{|l|}{ Race/ethnicity } & \multirow{6}{*}{$<0.001$} \\
\hline Caucasian & 48.9 & 45.1 & 56.0 & 55.4 & \\
\hline African American & 13.7 & 14.2 & 12.1 & 13.2 & \\
\hline Hispanic & 11.1 & 13.4 & 8.6 & 6.8 & \\
\hline Asian or Other & 8.6 & 9.9 & 8.1 & 5.9 & \\
\hline Missing & 17.7 & 17.5 & 15.2 & 18.7 & \\
\hline \multicolumn{5}{|l|}{ Socioeconomic status } & \multirow{6}{*}{$<0.001$} \\
\hline Lower quartile & 27.4 & 25.5 & 27.9 & 31.2 & \\
\hline 2nd quartile & 25.7 & 25.7 & 23.0 & 26.3 & \\
\hline 3rd quartile & 24.6 & 24.0 & 26.2 & 25.5 & \\
\hline Upper quartile & 19.5 & 21.6 & 21.8 & 15.0 & \\
\hline Missing & 2.7 & 3.2 & 1.2 & 2.1 & \\
\hline \multicolumn{5}{|l|}{ Insurance status } & \multirow{5}{*}{$<0.001$} \\
\hline Private & 47.3 & 46.5 & 49.7 & 48.4 & \\
\hline Medicare & 24.4 & 27.8 & 34.5 & 15.7 & \\
\hline Medicaid & 16.4 & 15.8 & 7.2 & 19.3 & \\
\hline Self pay or other & 12.0 & 10.0 & 8.6 & 16.6 & \\
\hline Alcohol abuse & 6.7 & 3.8 & 5.5 & 12.7 & $<0.001$ \\
\hline Anemia (deficiency) & 20.5 & 22.0 & 20.7 & 17.6 & 0.001 \\
\hline Arthritis & 2.2 & 2.4 & 2.3 & 1.8 & 0.34 \\
\hline Blood loss anemia & 1.4 & 1.5 & 1.7 & 1.1 & 0.40 \\
\hline $\mathrm{CHF}$ & 4.8 & 5.5 & 5.8 & 3.3 & 0.001 \\
\hline Chronic pulmonary disease & 12.7 & 9.1 & 20.4 & 18.4 & $<0.001$ \\
\hline Coagulopathy & 5.2 & 5.6 & 4.0 & 4.7 & 0.25 \\
\hline Diabetes mellitus & 10.9 & 12.1 & 10.6 & 8.5 & $<0.001$ \\
\hline Diabetes w/ complications & 0.9 & 1.2 & 0.9 & 0.3 & 0.002 \\
\hline Drug abuse & 5.7 & 3.5 & 3.2 & 10.6 & $<0.001$ \\
\hline Hypertension & 65.3 & 64.6 & 69.3 & 66.0 & 0.17 \\
\hline Hypothyroidism & 6.8 & 7.1 & 10.6 & 5.4 & 0.001 \\
\hline Liver disease & 1.3 & 1.4 & 1.4 & 1.2 & 0.76 \\
\hline Obesity & 7.5 & 7.3 & 9.5 & 7.5 & 0.34 \\
\hline Peripheral vascular disease & 6.2 & 6.0 & 5.5 & 6.7 & 0.51 \\
\hline Pulmonary hypertension & 2.8 & 3.1 & 3.7 & 2.0 & 0.03 \\
\hline Renal failure & 2.6 & 3.2 & 3.7 & 1.3 & $<0.001$ \\
\hline Valvular disease & 2.7 & 3.1 & 2.9 & 1.9 & 0.04 \\
\hline Weight loss & 10.5 & 11.7 & 8.6 & 8.4 & $<0.001$ \\
\hline \multicolumn{5}{|l|}{ No. of comorbidities } & \multirow{5}{*}{0.02} \\
\hline 0 & 15.3 & 16.2 & 13.5 & 13.7 & \\
\hline 1 & 30.1 & 30.0 & 26.4 & 31.1 & \\
\hline 2 & 27.4 & 27.9 & 29.9 & 26.1 & \\
\hline$\geq 3$ & 27.2 & 26.0 & 30.2 & 29.1 & \\
\hline Mean NIS-SAH Severity Scale score (SD) & $6.8(11.8)$ & $7.5(12.7)$ & $6.9(12.5)$ & $5.2(9.7)$ & $<0.001$ \\
\hline Microsurgical clipping & 42.1 & 42.5 & 33.3 & 43.1 & 0.003 \\
\hline Intracerebral hemorrhage & 10.5 & 11.4 & 11.5 & 8.4 & 0.002 \\
\hline Cerebral edema & 14.7 & 16.2 & 13.5 & 11.8 & $<0.001$ \\
\hline Craniectomy & 1.4 & 1.8 & 0.9 & 0.7 & 0.003 \\
\hline
\end{tabular}


» CONTINUED FROM PAGE 448

TABLE 1. Demographics of the NIS study population, stratified by cigarette smoking status

\begin{tabular}{|c|c|c|c|c|c|}
\hline Variable & Total Population & Nonsmoker & Former Smoker & Current Smoker & p Value \\
\hline \multicolumn{5}{|c|}{ Hospital metropolitan area (population) } & \multirow{5}{*}{$<0.001$} \\
\hline$\geq 1,000,000$ & 59.2 & 62.1 & 57.8 & 53.6 & \\
\hline $250,000-999,999$ & 15.4 & 15.6 & 11.8 & 15.7 & \\
\hline $50,000-249,999$ & 8.7 & 7.4 & 12.4 & 10.6 & \\
\hline$<50,000$ & 16.8 & 14.9 & 18.1 & 20.2 & \\
\hline \multicolumn{5}{|l|}{ Hospital size } & \multirow{3}{*}{0.08} \\
\hline Small/medium & 14.5 & 13.8 & 17.2 & 15.5 & \\
\hline Large & 85.5 & 86.2 & 82.8 & 84.5 & \\
\hline Teaching hospital & 88.4 & 88.7 & 90.2 & 87.6 & 0.27 \\
\hline \multicolumn{5}{|l|}{ Hospital region } & \multirow{5}{*}{$<0.001$} \\
\hline Northeast & 16.3 & 18.4 & 10.3 & 13.2 & \\
\hline Midwest & 24.6 & 20.9 & 29.0 & 31.1 & \\
\hline South & 33.8 & 33.3 & 32.2 & 35.2 & \\
\hline West & 25.4 & 27.4 & 28.5 & 20.6 & \\
\hline \multicolumn{5}{|l|}{ Yr of admission } & \multirow{4}{*}{0.07} \\
\hline 2009 & 30.3 & 31.2 & 26.4 & 29.3 & \\
\hline 2010 & 37.0 & 37.2 & 35.9 & 36.7 & \\
\hline 2011 & 32.7 & 31.5 & 37.6 & 34.1 & \\
\hline
\end{tabular}

276.1), and infections (595.0, 996.64, 481-486, 507.0, 997.31,38.x, 995.9x, 320.x, 041.x, 324.1, 790.7, 999.31, and 998.59). The proportion of patients who underwent tracheostomy $(311,312.1,312.9)$ and gastrostomy or jejunostomy $(431.1,431.9,463.2)$ was evaluated. An extended hospitalization was defined as a hospital stay longer than the upper quartile of the interquartile range of the entire study population. A nonroutine discharge was defined as any discharge other than to home; discharge to institutional care was a designation of a nursing facility, extended care facility, or hospice, but does not include discharge to acute rehabilitation. Analyses of tracheostomy or gastrostomy, length of stay, and discharge disposition were only conducted for patients discharged alive, to distinguish these outcomes from mortality.

Finally, the composite NIS-SAH outcome measure was calculated. This externally validated end point defines a poor outcome based on in-hospital mortality, discharge to institutional care, or tracheostomy or gastrostomy placement, and has been shown to have $95 \%$ agreement with a modified Rankin scale score greater than $3 .{ }^{50}$

\section{Missing Data}

Patients with missing data for covariates (race/ethnicity and socioeconomic status) were placed in a separate stratum for that variable to maintain the total study population and appropriately account for missing data. Although data on most outcomes including death and nonroutine discharge were available from all states, data are not provided on discharge to institutional care (which is a component of the NIS-SAH outcome measure) for patients from California, Maryland, or Maine. Patients from these states constituted $12.1 \%(n=700)$ of the patient population and were excluded from analyses of discharge to institutional care or of poor outcome. A sensitivity analysis was performed using multiple imputations for the missing data on discharge status on these patients.

\section{Sensitivity and Subgroup Analyses}

A matched-pairs sensitivity analysis was performed after matching current smokers and nonsmokers by age, sex, NIS-SAH severity scale score, and number of comorbidities. An additional sensitivity analysis performed propensity adjustment by evaluating the probability of smoking based on patient demographics and comorbidities, and this propensity score was used as a covariate in regression models. Another sensitivity analysis accounted for the potential misclassification of smoking status based on the calculated classification accuracy of ICD-9-CM coding from our institutional review. Moreover, a subgroup of patients with a poor grade, defined as an NIS-SAH severity scale score in the upper quartile for the entire population, was evaluated. Additional regression constructs analyzed the interaction between smoking and age, sex, or treatment modality for aneurysm repair, as well as between patient age and severity of SAH.

\section{Additional Data Source}

To evaluate for consistency with the NIS, data were extracted from the prospective NSQIP registry (2007-2013), which has been previously used to analyze patients with SAH. ${ }^{2,46}$ The NSQIP was exempted from individual review by our IRB. Patients were included who were 1) 18 
years of age or older, 2) had an ICD-9-CM diagnosis code for SAH or intracerebral hemorrhage (430, 431, 432.9), and 3) underwent a craniotomy under general anesthesia for clipping of a carotid (CPT codes 61697, 61700, 61703, or 61705) or vertebrobasilar circulation intracranial aneurysm (CPT codes 61698 or 61702) by a neurosurgeon. The NSQIP does not systematically collect data on intracranial endovascular interventions. Patients were stratified by cigarette smoking, which is defined by the NSQIP as having smoked any cigarettes within the past year, and is directly recorded by surgical reviewers, not designated by ICD-9-CM codes. ${ }^{1}$

Covariates extracted were patient age, sex, race or ethnicity, American Society of Anesthesiologists (ASA) class, baseline functional status, body habitus, comorbidities (hypertension, cardiac disease, chronic obstructive pulmonary disease [COPD], diabetes mellitus, hyponatremia, and alcohol abuse), endotracheal intubation, case urgency, and operative time. The 30-day outcomes evaluated were mortality, complications, length of hospital stay, reoperation, and discharge disposition. Complications extracted were neurological (cerebrovascular accident, intracranial hemorrhage, or coma), cardiac (cardiac arrest or acute myocardial infarction), extubation failure, prolonged mechanical ventilation, venous thromboembolic, infectious, and packed red blood cell transfusions. Reoperation is defined by the NSQIP as any return to the operating room, including tracheostomy, gastrostomy, or ventricular shunt placement.

\section{Statistical Analyses}

Statistical analyses were performed using Stata (version 13, StataCorp LLC) accounting for the survey design of the NIS, with the hospital identification as the sampling unit, the discharge weight as the sampling weight variable, and the NIS stratum as the strata. Descriptive statistics were performed and baseline characteristics were compared using the chi-square test for categorical variables and the ANOVA for continuous variables. Thereafter, multivariable logistic regression models were constructed with all analyzed characteristics as covariates, given their association with SAH outcomes. Conditional logistic regression analyzed the matched analysis, after including matching criteria. Concordance statistics assessed the discrimination of regression constructs. A p value $<0.05$ was considered significant.

\section{Results \\ Validation of ICD-9-CM Codes}

Among 275 patients with cerebral aneurysms treated at our institution, 39.3\% $(\mathrm{n}=108,95 \%$ CI $33.4 \%-45.1 \%)$ were current smokers and $28.0 \%(\mathrm{n}=77,95 \%$ CI $22.7 \%-$ $33.3 \%$ ) had a history of smoking. When evaluating the ICD-9-CM code for current tobacco use, the accuracy was $82.9 \%$, sensitivity $62.6 \%$, specificity $96.4 \%$, positive predictive value $91.8 \%$, and negative predictive value $79.7 \%$. The ICD-9-CM code for a history of tobacco use was less robustly coded: the accuracy was $74.9 \%$, sensitivity $36.3 \%$, specificity $89.9 \%$, positive predictive value $58.3 \%$, and negative predictive value $78.4 \%$.

\section{Demographics of the NIS Population}

Within the NIS patient population, 5784 patients were included, and $37.1 \%$ ( $\mathrm{n}=2148,95 \%$ confidence interval [CI] 35.9\%-38.4\%) were documented smokers. Of these patients, 31.1\% ( $\mathrm{n}=1800,95 \%$ CI $29.9 \%-32.3 \%)$ had a diagnosis code indicating current tobacco use and $6.0 \%$ $(\mathrm{n}=348,95 \%$ CI $5.4 \%-6.6 \%)$ a history of tobacco use. The demographics of the NIS population are stratified by smoking status in Table 1. The differences in the crude rates of in-hospital mortality, discharge to institutional care, and poor outcome as stratified by cigarette smoking status are shown in Fig. 1.

\section{Multivariable Regression Models}

Multivariable logistic regression models evaluating the association of smoking with outcomes are shown in Table 2 . Due to differences in patient age, sex, number of comorbidities, and severity of SAH by smoking status, a matchedpairs analysis compared current smokers to nonsmokers after matching on these 4 criteria (Table 2). In both the total population and the matched pair analysis, there was no difference in mortality, total complications, neurological complications, or delayed cerebral ischemia. However, cigarette smoking was associated with decreased odds of a poor outcome in both the total population (odds ratio
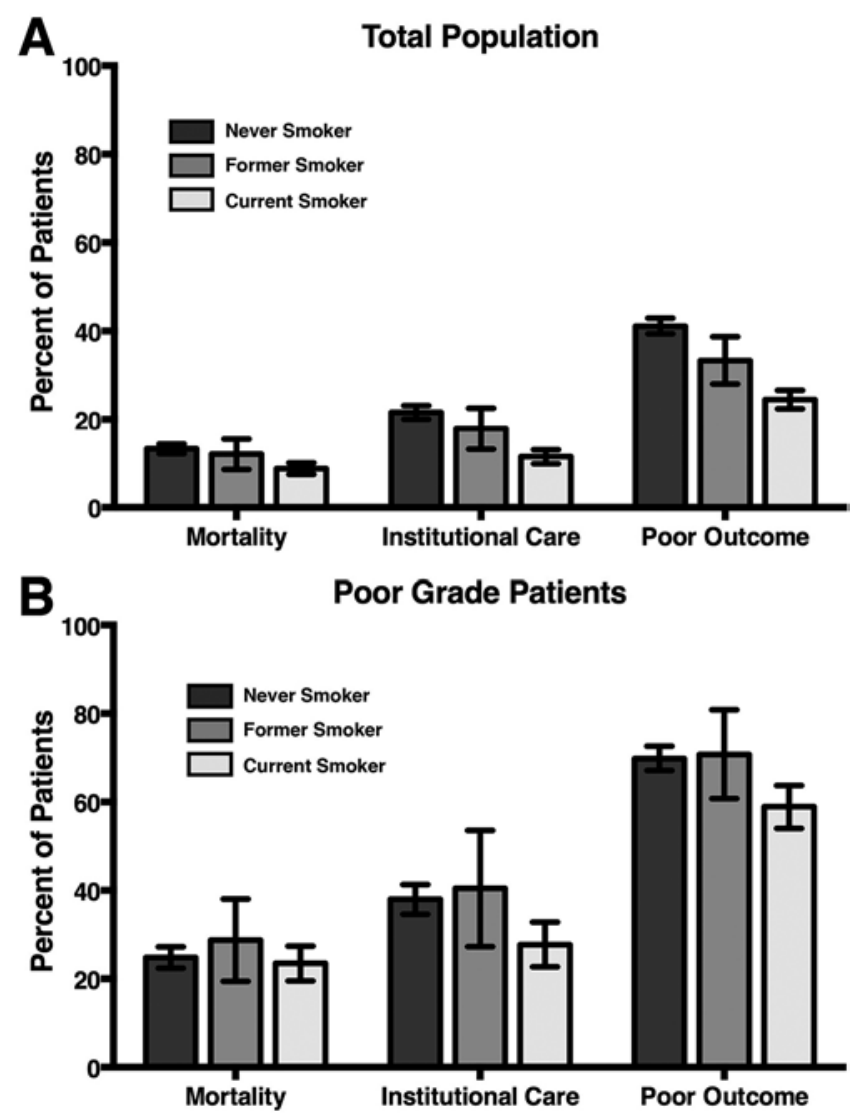

FIG. 1. Bar graphs showing differences in the crude rates (and associated errors) of in-hospital mortality, discharge to institutional care, and poor outcome (defined by the NIS-SAH outcome measure) in the total population $(\mathbf{A})$ and the subgroup of poor-grade patients $(\mathbf{B})$, stratified by cigarette smoking status. 
TABLE 2. Multivariable logistic regression models evaluating the association of cigarette smoking with outcomes after SAH in the NIS population

\begin{tabular}{|c|c|c|c|c|c|c|c|c|}
\hline \multirow[b]{2}{*}{ Outcome } & \multicolumn{5}{|c|}{ Total Population } & \multicolumn{3}{|c|}{ Matched-Pairs Analysis } \\
\hline & Crude \% & OR & $95 \% \mathrm{Cl}$ & p Value* & C Statistic & OR & $95 \% \mathrm{Cl}$ & p Value* \\
\hline \multicolumn{9}{|l|}{ In-hospital mortality } \\
\hline Nonsmokers & 13.3 & Ref & - & - & \multirow{3}{*}{0.80} & Ref & - & - \\
\hline Former smokers & 12.1 & 0.79 & $0.52-1.18$ & 0.24 & & - & - & - \\
\hline Current smokers & 8.8 & 0.87 & $0.69-1.09$ & 0.23 & & 1.56 & $0.75-3.22$ & 0.23 \\
\hline \multicolumn{9}{|l|}{ Total complications } \\
\hline Nonsmokers & 84.6 & Ref & - & - & \multirow{3}{*}{0.83} & Ref & - & - \\
\hline Former smokers & 82.2 & 0.80 & $0.55-1.14$ & 0.22 & & - & - & - \\
\hline Current smokers & 78.9 & 0.91 & $0.77-1.09$ & 0.31 & & 1.36 & $0.94-1.96$ & 0.10 \\
\hline \multicolumn{9}{|l|}{ Neurological complications } \\
\hline Nonsmokers & 34.1 & Ref & - & - & \multirow{3}{*}{0.63} & Ref & - & - \\
\hline Former smokers & 32.2 & 0.95 & $0.74-1.22$ & 0.67 & & - & - & - \\
\hline Current smokers & 33.9 & 1.00 & $0.85-1.16$ & 0.95 & & 0.96 & $0.75-1.22$ & 0.71 \\
\hline \multicolumn{9}{|l|}{ Delayed cerebral ischemia } \\
\hline Nonsmokers & 14.9 & Ref & - & - & \multirow{3}{*}{0.65} & Ref & - & - \\
\hline Former smokers & 16.7 & 1.15 & $0.81-1.62$ & 0.44 & & - & - & - \\
\hline Current smokers & 17.8 & 1.16 & $0.95-1.40$ & 0.14 & & 0.85 & $0.60-1.19$ & 0.33 \\
\hline \multicolumn{9}{|c|}{ Gastrostomy or tracheostomy $(n=5100)$} \\
\hline Nonsmokers & 22.7 & Ref & - & - & \multirow{3}{*}{0.84} & Ref & - & - \\
\hline Former smokers & 13.7 & 0.54 & $0.36-0.82$ & 0.004 & & - & - & - \\
\hline Current smokers & 11.9 & 0.63 & $0.51-0.78$ & $<0.001$ & & 0.50 & $0.30-0.86$ & 0.01 \\
\hline \multicolumn{9}{|l|}{ Extended hospitalization $(n=5100)^{*}$} \\
\hline Nonsmokers & 26.7 & Ref & - & - & \multirow{3}{*}{0.77} & Ref & - & - \\
\hline Former smokers & 18.3 & 0.68 & $0.49-0.94$ & 0.02 & & - & - & - \\
\hline Current smokers & 16.2 & 0.63 & $0.52-0.76$ & $<0.001$ & & 0.47 & $0.30-0.73$ & 0.001 \\
\hline \multicolumn{9}{|l|}{ Nonroutine discharge $(n=5100)$} \\
\hline Nonsmokers & 62.0 & Ref & - & - & \multirow{3}{*}{0.81} & Ref & - & - \\
\hline Former smokers & 55.6 & 0.73 & $0.56-0.95$ & 0.02 & & - & - & - \\
\hline Current smokers & 47.8 & 0.76 & $0.66-0.89$ & $<0.001$ & & 0.73 & $0.53-1.00$ & 0.05 \\
\hline \multicolumn{9}{|c|}{ Discharge to institutional care $(n=4487)$} \\
\hline Nonsmokers & 21.6 & Ref & - & - & \multirow{3}{*}{0.83} & Ref & - & - \\
\hline Former smokers & 17.9 & 0.73 & $0.48-1.12$ & 0.15 & & - & - & - \\
\hline Current smokers & 11.5 & 0.71 & $0.57-0.89$ & 0.002 & & 0.24 & $0.08-0.69$ & 0.008 \\
\hline \multicolumn{9}{|c|}{ Poor outcome (by the NIS-SAH outcome measure, $n=5084$ ) } \\
\hline Nonsmokers & 41.1 & Ref & - & - & \multirow{3}{*}{0.85} & Ref & - & - \\
\hline Former smokers & 33.3 & 0.66 & $0.47-0.94$ & 0.02 & & - & - & - \\
\hline Current smokers & 24.5 & 0.65 & $0.55-0.77$ & $<0.001$ & & 0.47 & $0.30-0.72$ & 0.001 \\
\hline
\end{tabular}

C statistic = concordance statistic; Ref $=$ reference .

All multivariable logistic regression models include characteristics described in Table 1 as covariates, including patient age, sex, race/ethnicity, socioeconomic status, insurance status, comorbidities, NIS-SAH severity scale, and hospital characteristics. In all relevant tables, regression analyses of tracheostomy or gastrostomy placement, length of stay, and discharge disposition ("nonroutine discharge") were only performed for patients discharged from the hospital alive. Boldface type indicates statistical significance.

* In all relevant tables, an extended hospitalization was defined as longer than 24 days, the upper quartile for the entire population.

[OR] 0.65, 95\% CI 0.55-0.77, $\mathrm{p}<0.001)$ and the matched pair analysis (OR $0.47,95 \%$ CI $0.30-0.72, p=0.001)$. In a sensitivity analysis in which missing discharge status was imputed, smoking remained associated with lower odds of discharge to institutional care and a poor outcome (data not shown).

\section{Sensitivity and Subgroup Analyses}

Given the potential for misclassification of smoking by ICD-9-CM coding, a sensitivity analysis was performed accounting for its sensitivity, specificity, and positive and negative predictive values (calculated from our institutional data). In this analysis, after excluding prior smokers, 
TABLE 3. Sensitivity analyses evaluating the association of cigarette smoking with outcomes after SAH in the NIS population

\begin{tabular}{|c|c|c|c|c|c|c|}
\hline \multirow[b]{2}{*}{ Outcome } & \multicolumn{3}{|c|}{ ICD-9-CM Codes Sensitivity Analysis } & \multicolumn{3}{|c|}{ Propensity Score* } \\
\hline & OR & $95 \% \mathrm{Cl}$ & p Value & OR & $95 \% \mathrm{Cl}$ & $\mathrm{p}$ Value \\
\hline \multicolumn{7}{|l|}{ In-hospital mortality } \\
\hline Nonsmokers & Ref & - & - & Ref & - & - \\
\hline Current smokers & 0.85 & $0.71-1.02$ & 0.08 & 0.97 & $0.87-1.08$ & 0.54 \\
\hline \multicolumn{7}{|l|}{ Total complications } \\
\hline Nonsmokers & Ref & - & - & Ref & - & - \\
\hline Current smokers & 1.01 & $0.86-1.19$ & 0.92 & 0.95 & $0.88-1.02$ & 0.17 \\
\hline \multicolumn{7}{|l|}{ Neurological complications } \\
\hline Nonsmokers & Ref & - & - & Ref & - & - \\
\hline Current smokers & 1.01 & $0.90-1.13$ & 0.87 & 1.00 & $0.93-1.09$ & 0.92 \\
\hline \multicolumn{7}{|l|}{ Delayed cerebral ischemia } \\
\hline Nonsmokers & Ref & - & - & Ref & - & - \\
\hline Current smokers & 1.10 & $0.94-1.28$ & 0.22 & 1.07 & $0.87-1.18$ & 0.18 \\
\hline \multicolumn{7}{|l|}{ Gastrostomy or tracheostomy } \\
\hline Nonsmokers & Ref & - & - & Ref & - & - \\
\hline Current smokers & 0.77 & $0.64-0.92$ & 0.005 & 0.80 & $0.30-0.86$ & 0.01 \\
\hline \multicolumn{7}{|l|}{ Extended hospitalization } \\
\hline Nonsmokers & Ref & - & - & Ref & - & - \\
\hline Current smokers & 0.77 & $0.66-0.91$ & 0.002 & 0.80 & $0.74-0.88$ & $<0.001$ \\
\hline \multicolumn{7}{|l|}{ Nonroutine discharge } \\
\hline Nonsmokers & Ref & - & - & Ref & - & - \\
\hline Current smokers & 0.84 & $0.73-0.96$ & 0.01 & 0.88 & $0.82-0.95$ & 0.001 \\
\hline \multicolumn{7}{|l|}{ Discharge to institutional care } \\
\hline Nonsmokers & Ref & - & - & Ref & - & - \\
\hline Current smokers & 0.87 & $0.73-1.05$ & 0.14 & 0.81 & $0.73-0.91$ & $<0.001$ \\
\hline \multicolumn{7}{|c|}{ Poor outcome (by the NIS-SAH outcome measure) } \\
\hline Nonsmokers & Ref & - & - & Ref & - & - \\
\hline Current smokers & 0.76 & $0.65-0.89$ & $<0.001$ & 0.81 & $0.75-0.89$ & $<0.001$ \\
\hline
\end{tabular}

The ICD-9-CM codes sensitivity analysis included reclassification of a random set of 148 classified smokers and 738 classified nonsmokers, to mimic the expected distribution of smoking status based on our institutional validation of ICD-9-CM coding for smoking among patients with cerebral aneurysms. These multivariable logistic regression models include characteristics described in Table 1 as covariates, including patient age, sex, race/ethnicity, socioeconomic status, insurance status, comorbidities, NIS-SAH severity scale score, and hospital characteristics. Boldface type indicates statistical significance.

* The propensity-score adjusted sensitivity analysis only included the propensity score as a covariate, which was based on the probability that an individual was a documented smoker based on patient demographics and comorbidities.

smoking was randomly reclassified for 148 documented smokers to nonsmokers and for 738 documented nonsmokers as smokers. This created a sample mimicking the expected distribution of smoking status if the ICD-9-CM codes had perfect classification. In this analysis, smoking remained associated with decreased odds of tracheostomy or gastrostomy placement, an extended hospitalization, nonroutine discharge, and poor outcome (Table 3), suggesting that smoking misclassification alone does not account for the observed statistical differences. An additional sensitivity analysis was performed of outcomes using propensity score adjustment, with similar associations as the primary analysis (Table 3 ). There is a potential reporting bias, whereby tobacco use may be less robustly documented in poor-grade patients with altered sensorium. Thus, a subgroup analysis was performed exclusively of patients with documented poor grades (Table 4), the results of which were similar to the primary analysis.

\section{Interactions}

Additional regression constructs evaluated an interaction between smoking and patient age, sex, or treatment modality used for aneurysm repair in mortality, delayed cerebral ischemia, or poor outcome. No effect measure modification was observed by age or sex. However, after accounting for the interaction of smoking and treatment modality, smoking was associated with decreased odds of in-hospital mortality (OR $0.69,95 \%$ CI $0.50-0.96, \mathrm{p}$ $=0.03$ ), increased odds of delayed cerebral ischemia (OR $1.29,95 \%$ CI 1.02-1.64, $\mathrm{p}=0.03$ ), and decreased odds of a poor outcome (OR 0.53, 95\% CI 0.41-0.69, p = 0.001). Finally, an interaction between patient age and severity of SAH (using the NIS-SAH severity scale) was considered: while the interaction itself was significant $(\mathrm{p}=0.02)$, suggesting a synergistic relationship between age and severity of SAH, the association of smoking with death, delayed 
TABLE 4. Multivariable logistic regression evaluating the outcomes of poor-grade patients, stratified by cigarette smoking

\begin{tabular}{|c|c|c|c|c|c|}
\hline Outcome & Crude $\%$ & OR & $95 \% \mathrm{Cl}$ & p Value & C Statistic \\
\hline \multicolumn{6}{|l|}{ In-hospital mortality $(n=1785)$} \\
\hline Nonsmokers & 24.8 & Ref & - & - & \multirow{3}{*}{0.72} \\
\hline Former smokers & 28.7 & 0.97 & $0.57-1.65$ & 0.92 & \\
\hline Current smokers & 23.4 & 1.08 & $0.80-1.45$ & 0.62 & \\
\hline \multicolumn{6}{|l|}{ Neurological complications ( $\mathrm{n}=1785$ ) } \\
\hline Nonsmokers & 42.1 & Ref & - & - & \multirow{3}{*}{0.63} \\
\hline Former smokers & 38.3 & 0.86 & $0.53-1.39$ & 0.53 & \\
\hline Current smokers & 45.2 & 0.98 & $0.76-1.26$ & 0.85 & \\
\hline \multicolumn{6}{|l|}{ Delayed cerebral ischemia $(n=1785)$} \\
\hline Nonsmokers & 17.4 & Ref & - & - & \multirow{3}{*}{0.68} \\
\hline Former smokers & 16.0 & 0.86 & $0.45-1.63$ & 0.65 & \\
\hline Current smokers & 22.6 & 1.20 & $0.88-1.64$ & 0.24 & \\
\hline \multicolumn{6}{|c|}{ Gastrostomy or tracheostomy $(n=1344)$} \\
\hline Nonsmokers & 49.5 & Ref & - & - & \multirow{3}{*}{0.71} \\
\hline Former smokers & 44.8 & 0.89 & $0.52-1.53$ & 0.62 & \\
\hline Current smokers & 38.9 & 0.74 & $0.58-0.95$ & 0.02 & \\
\hline \multicolumn{6}{|l|}{ Extended hospitalization $(n=1344)$} \\
\hline Nonsmokers & 52.0 & Ref & - & - & \multirow{3}{*}{0.68} \\
\hline Former smokers & 47.8 & 0.95 & $0.56-1.61$ & 0.85 & \\
\hline Current smokers & 45.9 & 0.79 & $0.60-1.05$ & 0.10 & \\
\hline \multicolumn{6}{|c|}{ Discharge to institutional care $(n=1168)$} \\
\hline Nonsmokers & 38.0 & Ref & - & - & \multirow{3}{*}{0.77} \\
\hline Former smokers & 40.4 & 0.94 & $0.52-1.70$ & 0.83 & \\
\hline Current smokers & 27.7 & 0.69 & $0.49-0.96$ & 0.03 & \\
\hline \multicolumn{6}{|c|}{ Poor outcome (by the NIS-SAH outcome measure, $n=1550$ ) } \\
\hline Nonsmokers & 69.8 & Ref & - & - & \multirow{3}{*}{0.74} \\
\hline Former smokers & 70.7 & 0.89 & $0.52-1.52$ & 0.66 & \\
\hline Current smokers & 58.9 & 0.75 & $0.58-0.96$ & 0.03 & \\
\hline
\end{tabular}

All multivariable logistic regression models include characteristics described in Table 1 as covariates, including patient age, sex, race/ethnicity, socioeconomic status, insurance status, comorbidities, NIS-SAH severity scale, and hospital characteristics. Boldface type indicates statistical significance.

cerebral ischemia, and a poor outcome remained similar to the primary analysis (data not shown).

\section{NSQIP Population}

Within the NSQIP population, 373 patients were included, $36.5 \%(\mathrm{n}=136,95 \%$ CI $31.6 \%-41.4 \%)$ of whom were smokers, and their baseline demographics are compared in Table 5. Similar to the NIS population, smokers were significantly younger and more likely to abuse alcohol. The crude rates of reoperation, nonroutine discharge, and discharge to institutional care were lower for smokers. However, in multivariable analyses (Table 6), these differences were not statistically significant, likely due to the comparatively small sample size of this population.

\section{Discussion}

Because cigarette smoke is a mixture of more than 4000 chemicals, the exact mechanisms by which smoking promotes cerebral aneurysm formation remain largely unknown. ${ }^{13,19,24}$ Few studies have evaluated how the outcomes after aneurysmal SAH vary by smoking status. In a single-institution study, Lasner et al. found that smoking and Fisher Grade 3 were predictors of symptomatic vasospasm..$^{40}$ Likewise, when evaluating 3441 patients from 5 randomized controlled trials, Weir et al. reported that smoking was associated with younger age at rupture and a 1.2 times higher odds of clinical vasospasm; however, mortality and neurological status were not examined. ${ }^{51}$ Probereskin reported that younger age and cigarette smoking were protective against mortality after rupture, ${ }^{44}$ hypothesizing that smoking may cause immediate vasospasm and platelet activation, diminishing the initial volume of hemorrhage. ${ }^{44}$ Nonetheless, this study was criticized for not fully accounting for confounding. ${ }^{32}$ Krishnamurthy et al. found a higher rate of delayed neurological deterioration for smokers, but no difference in Glasgow Outcome Scale (GOS) scores in multivariable models. ${ }^{37}$

A notable observation from two retrospective studies was that transdermal nicotine replacement after SAH was associated with superior outcomes among smokers. After matching by age, Hunt and Hess grade, and radiographic findings, Seder et al. found that smokers who received nicotine replacement had significantly decreased odds 
of death 3 months after rupture, but similar rates of delayed cerebral ischemia, compared with smokers who did not receive nicotine. ${ }^{45}$ Likewise, Carandang et al. found no significant difference in angiographic vasospasm, but lower odds of clinical vasospasm and a poor GOS score among smokers who received nicotine replacement compared with smokers treated without nicotine. ${ }^{12}$ Moreover, in an analysis of patients with ischemic stroke enrolled in the "Get With The Guidelines-Stroke" registry, Ali et al. found decreased odds of death for smokers. ${ }^{3}$

In this study, the NIS administrative claims database and the NSQIP surgical registry were used to evaluate the association of smoking with outcomes after aneurysmal SAH. In both populations, smokers were significantly younger and had increased comorbidities; given the morbidity associated with $\mathrm{SAH}$, this earlier age of rupture highlights the negative ramifications of smoking in patients with cerebral aneurysms. However, in both data sets, smoking was associated with lower crude rates of reoperation, an extended hospitalization, and discharge to institutional care. The magnitude of the difference was comparable between the two data sets in extended hospitalization (NIS $26.7 \%$ vs $16.2 \%$, NSQIP $29.3 \%$ vs $21.1 \%$ ), the reduction of reoperation (NIS $22.7 \%$ vs $11.9 \%$, NSQIP $20.5 \%$ vs $13.0 \%$ ), and discharge to institutional care (NIS $21.6 \%$ vs $11.5 \%$, NSQIP $16.4 \%$ vs $10.1 \%$ ). Additionally, in the NIS population, smoking was associated with decreased adjusted odds of tracheostomy or gastrostomy, discharge to institutional care, and poor outcome in the entire population, the matched-pairs analysis, and the subgroup of poor-grade patients. Although smoking was not associated with delayed cerebral ischemia in the total population, after accounting for the interaction of cigarette smoking and microsurgical clipping, smoking was associated with increased odds of delayed cerebral ischemia. This may partially explain why some prior studies showed that smoking was associated with vasospasm, as these studies were primarily analyzing patients treated surgically; some research has suggested that endovascular treatment is associated with decreased delayed cerebral ischemia, ${ }^{23}$ which may be particularly pertinent for smokers.

One possible explanation for the superior outcomes associated with smoking may be due to the neuroprotective effects of nicotine. The impact of nicotine on the cerebral vasculature has been reviewed elsewhere; Carandang et al. concluded from a comprehensive review that nicotine might have antiinflammatory and neurogenic vasodilatory effects that are mediated by nicotinic acetylcholine receptors on intracranial vessels. ${ }^{12}$ Nevertheless, this does not necessarily mean that nicotine administration to nonsmokers would have clinical benefit, and any underlying pathophysiology cannot be discerned from the present study.

However, the differences in outcomes by smoking status may also be due to bias from study design. One potential source of bias is confounding, including by age, sex, number of comorbidities, or severity of SAH, all of which differed significantly according to smoking status. Due to the possibility of residual confounding, a matched-pairs sensitivity analysis was performed, which had similar statistical associations with the primary analysis. Reporting bias is
TABLE 5. Demographics of the NSQIP study population, stratified by smoking status

\begin{tabular}{|c|c|c|c|c|}
\hline \multirow[b]{2}{*}{ Characteristic } & \multirow{2}{*}{$\begin{array}{c}\text { Total } \\
\text { Population }\end{array}$} & \multicolumn{2}{|c|}{ Smoking Status } & \multirow{2}{*}{$\begin{array}{c}\mathrm{p} \\
\text { Value }\end{array}$} \\
\hline & & Smoker & Nonsmoker & \\
\hline No. of patients & 373 & 136 & 237 & \\
\hline Mean age in yrs (SD) & $54.9(13.3)$ & $51.9(10.1)$ & $56.6(14.6)$ & 0.001 \\
\hline Female sex & 71.1 & 66.9 & 73.4 & 0.18 \\
\hline \multicolumn{4}{|l|}{ Race/ethnicity } & \multirow{6}{*}{0.02} \\
\hline Caucasian & 45.6 & 48.5 & 43.9 & \\
\hline African American & 14.8 & 19.9 & 11.8 & \\
\hline Hispanic & 9.7 & 5.2 & 12.2 & \\
\hline Asian & 7.8 & 4.4 & 9.7 & \\
\hline Other or not reported & 22.3 & 22.1 & 22.4 & \\
\hline Hypertension & 46.4 & 43.4 & 48.1 & 0.38 \\
\hline \multicolumn{4}{|l|}{$\begin{array}{l}\text { Prior cardiac revascu- } \\
\text { larization }\end{array}$} & \multirow{4}{*}{0.11} \\
\hline No & 60.1 & 66.9 & 56.1 & \\
\hline Yes & 3.2 & 2.2 & 3.8 & \\
\hline Missing & 36.7 & 30.9 & 40.1 & \\
\hline COPD & 3.5 & 2.9 & 3.8 & 0.66 \\
\hline Diabetes mellitus & 9.7 & 11.0 & 8.9 & 0.50 \\
\hline \multicolumn{4}{|l|}{ Alcohol abuse } & \multirow{4}{*}{0.001} \\
\hline No & 58.2 & 58.8 & 57.8 & \\
\hline Yes & 5.1 & 10.3 & 2.1 & \\
\hline Missing & 36.7 & 30.9 & 40.1 & \\
\hline \multicolumn{4}{|l|}{ Body mass index } & \multirow{5}{*}{0.11} \\
\hline Non-obese & 56.6 & 64.7 & 51.9 & \\
\hline Obese & 23.1 & 17.7 & 26.2 & \\
\hline Morbidly obese & 6.4 & 5.9 & 6.8 & \\
\hline Missing & 13.9 & 11.8 & 15.2 & \\
\hline \multicolumn{4}{|l|}{$\begin{array}{l}\text { ASA physical status } \\
\text { class }\end{array}$} & \multirow{4}{*}{0.32} \\
\hline 1 or 2 & 8.3 & 5.9 & 9.7 & \\
\hline 3 & 34.9 & 38.2 & 32.9 & \\
\hline 4 or 5 & 56.8 & 55.9 & 57.4 & \\
\hline \multicolumn{4}{|l|}{ Functional status } & \multirow{4}{*}{0.97} \\
\hline Independent & 78.3 & 79.4 & 77.6 & \\
\hline Dependent & 20.9 & 21.5 & 19.9 & \\
\hline Missing & 0.8 & 0.7 & 0.8 & \\
\hline $\begin{array}{l}\text { Carotid circulation } \\
\text { aneurysm }\end{array}$ & 83.7 & 85.3 & 82.7 & 0.51 \\
\hline Preop ventilation & 30.6 & 24.3 & 34.2 & 0.045 \\
\hline \multicolumn{4}{|l|}{ Preop sodium (mEq/L) } & \multirow{4}{*}{0.76} \\
\hline$\geq 135$ & 84.2 & 82.4 & 85.2 & \\
\hline$<135$ & 12.6 & 14.0 & 11.8 & \\
\hline Missing & 3.2 & 3.7 & 3.0 & \\
\hline Emergency op & 60.6 & 55.9 & 63.3 & 0.16 \\
\hline \multicolumn{4}{|l|}{ Op time (mins) } & \multirow{4}{*}{0.53} \\
\hline$<270$ & 52.8 & 51.5 & 53.6 & \\
\hline $270-330$ & 21.2 & 24.3 & 19.4 & \\
\hline$>330$ & 26.0 & 24.3 & 27.0 & \\
\hline
\end{tabular}

All data are presented as percentages, with the exception of patient age. Boldface type indicates statistical significance. 
TABLE 6. Multivariable logistic regression models evaluating the outcomes of the NSQIP patient population, stratified by smoking status

\begin{tabular}{|c|c|c|c|c|c|c|}
\hline \multirow[b]{2}{*}{ Variable } & \multicolumn{2}{|c|}{ Crude $\%$} & \multirow[b]{2}{*}{ OR } & \multirow[b]{2}{*}{$95 \% \mathrm{Cl}$} & \multirow[b]{2}{*}{ p Value } & \multirow[b]{2}{*}{ C Statistic } \\
\hline & Nonsmokers & Smokers & & & & \\
\hline 30-day mortality & 13.5 & 9.6 & 0.66 & $0.27-1.62$ & 0.37 & 0.88 \\
\hline Any complication & 56.1 & 48.5 & 0.81 & $0.48-1.38$ & 0.44 & 0.80 \\
\hline $\operatorname{Reop}(n=328)$ & 20.5 & 13.0 & 0.67 & $0.31-1.41$ & 0.29 & 0.78 \\
\hline Extended hospitalization $(n=328)$ & 29.3 & 21.1 & 0.77 & $0.42-1.42$ & 0.41 & 0.75 \\
\hline Nonroutine discharge $(n=214)$ & 52.6 & 36.4 & 0.58 & $0.27-1.26$ & 0.17 & 0.82 \\
\hline Discharge to institutional care $(n=214)$ & 16.1 & 10.4 & 0.78 & $0.25-2.45$ & 0.67 & 0.82 \\
\hline
\end{tabular}

All multivariable logistic regression models include baseline characteristics described in Table 4 as covariates. Data on discharge disposition were only available from 2011 to 2014.

an additional concern: smoking may be less robustly documented in patients with poor grade and altered sensorium, spuriously causing smoking to appear to be associated with superior outcomes. ${ }^{32}$ Therefore, a subgroup analysis was performed exclusively of patients with a documented poor grade, in which smoking remained associated with decreased odds of tracheostomy or gastrostomy and of a poor outcome.

There are many limitations of this study. First, clinical data were recorded in the NIS using ICD-9-CM indicators. The prevalence of tobacco use was similar in the two data sets: $37.1 \%$ in the NIS population (of whom $31.1 \%$ were current smokers) and $36.5 \%$ in the NSQIP population (where smoking is encoded directly by surgical reviewers and not through ICD-9-CM codes). Our institutional validation showed relatively high accuracy and positive and negative predictive values for the ICD-9-CM code for current tobacco use; encoding of a history of tobacco use was less robust. While the prevalence of smoking has decreased in the US, tobacco use may be undercoded in the NIS. However, a sensitivity analysis showed that misclassification of smoking status did not explain the observed significant effect estimates.

Moreover, data were not available on the duration or dose of cigarette smoking. While severity adjustment was performed using the externally validated NIS-SAH severity scale, other clinical variables not encoded through ICD-9-CM identifiers could not be evaluated, including Hunt and Hess grade, World Federation of Neurological Surgeons scale grade, Fisher grade, aneurysm size, and location. Additionally, a nuanced assessment of delayed cerebral ischemia was not possible, as ICD-9-CM identifiers do not distinguish between radiographic vasospasm, delayed cerebral ischemia, and delayed ischemic neurological deficit. Also, long-term data were not available.

However, there are many advantages to the use of large data sets to evaluate the association of cigarette smoking with outcomes after SAH. Both the NIS and NSQIP accrue patients from across the US, providing a broad perspective. The NIS includes several demographics, such as insurance status, race/ethnicity, and socioeconomic status, as well as comorbidities (including drug and alcohol abuse and hypertension) that may confound the association of cigarette smoking with outcomes and were included as covariates in multivariable analyses. Finally, the large sample size of the NIS provides greater statistical power to evaluate more subtle associations that may not be detected with smaller populations.

\section{Conclusions}

In this nationwide analysis, the association of cigarette smoking with outcomes after SAH was evaluated. Smoking was associated with a younger age of rupture and increased number of comorbidities, highlighting the negative impact of smoking in patients with cerebral aneurysms. However, cigarette smoking was also associated with paradoxically superior outcomes on many measures, including reduced odds of a poor outcome in the entire population and in poor-grade patients. These data, along with two recent studies showing that nicotine replacement therapy among smokers who sustain SAH was associated with superior outcomes, suggests that further research, including prospective studies, are needed to confirm these findings and further elucidate the underlying pathophysiology.

\section{Acknowledgments}

The American College of Surgeons National Surgical Quality Improvement Program and the hospitals participating in the ACS NSQIP are the source of the data used herein; they have not verified and are not responsible for the statistical validity of the data analysis or the conclusions derived by the authors.

\section{References}

1. Alan N, Seicean A, Seicean S, Schiltz NK, Neuhauser D, Weil RJ: Smoking and postoperative outcomes in elective cranial surgery. J Neurosurg 120:811-819, 2014

2. Alan N, Seicean A, Seicean S, Selman WR, Bambakidis NC: Impact of age on 30-day postoperative outcome of surgery for ruptured and unruptured intracranial aneurysms. J Neurointerv Surg 7:431-437, 2015

3. Ali SF, Smith EE, Bhatt DL, Fonarow GC, Schwamm LH: Paradoxical association of smoking with in-hospital mortality among patients admitted with acute ischemic stroke. J Am Heart Assoc 2:e000171, 2013

4. Anderson CS, Feigin V, Bennett D, Lin RB, Hankey G, Jamrozik K: Active and passive smoking and the risk of subarachnoid hemorrhage: an international population-based case-control study. Stroke 35:633-637, 2004

5. Attenello FJ, Reid P, Wen T, Cen S, Kim-Tenser M, Sanossian $\mathrm{N}$, et al: Evaluation of time to aneurysm treatment following subarachnoid hemorrhage: comparison of patients treated 
with clipping versus coiling. J Neurointerv Surg 8:373-377, 2016

6. Attenello FJ, Wang K, Wen T, Cen SY, Kim-Tenser M, Amar AP, et al: Health disparities in time to aneurysm clipping/ coiling among aneurysmal subarachnoid hemorrhage patients: a national study. World Neurosurg 82:1071-1076, 2014

7. Barker FG II, Amin-Hanjani S, Butler WE, Ogilvy CS, Carter BS: In-hospital mortality and morbidity after surgical treatment of unruptured intracranial aneurysms in the United States, 1996-2000: the effect of hospital and surgeon volume. Neurosurgery 52:995-1009, 2003

8. Bekelis K, Missios S, MacKenzie TA, Desai A, Fischer A, Labropoulos N, et al: Predicting inpatient complications from cerebral aneurysm clipping: the Nationwide Inpatient Sample 2005-2009. J Neurosurg 120:591-598, 2014

9. Bonita R: Cigarette smoking, hypertension and the risk of subarachnoid hemorrhage: a population-based case-control study. Stroke 17:831-835, 1986

10. Brinjikji W, Lanzino G, Kallmes DF, Cloft HJ: Cerebral aneurysm treatment is beginning to shift to low volume centers. J Neurointerv Surg 6:349-352, 2014

11. Brinjikji W, Lanzino G, Rabinstein AA, Kallmes DF, Cloft HJ: Age-related trends in the treatment and outcomes of ruptured cerebral aneurysms: a study of the nationwide inpatient sample 2001-2009. AJNR Am J Neuroradiol 34:10221027,2013

12. Carandang RA, Barton B, Rordorf GA, Ogilvy CS, Sims JR: Nicotine replacement therapy after subarachnoid hemorrhage is not associated with increased vasospasm. Stroke 42:30803086, 2011

13. Chalouhi N, Ali MS, Starke RM, Jabbour PM, Tjoumakaris SI, Gonzalez LF, et al: Cigarette smoke and inflammation: role in cerebral aneurysm formation and rupture. Mediators Inflamm 2012:271582, 2012

14. Claassen J, Bateman BT, Willey JZ, Inati S, Hirsch LJ, Mayer SA, et al: Generalized convulsive status epilepticus after nontraumatic subarachnoid hemorrhage: the nationwide inpatient sample. Neurosurgery 61:60-65, 2007

15. Crowley RW, Yeoh HK, Stukenborg GJ, Ionescu AA, Kassell NF, Dumont AS: Influence of weekend versus weekday hospital admission on mortality following subarachnoid hemorrhage. Clinical article. J Neurosurg 111:60-66, 2009

16. Danaei G, Ding EL, Mozaffarian D, Taylor B, Rehm J, Murray $\mathrm{CJ}$, et al: The preventable causes of death in the United States: comparative risk assessment of dietary, lifestyle, and metabolic risk factors. PLoS Med 6:e1000058, 2009

17. Davis MC, Broadwater DR, Amburgy JW, Harrigan MR: The clinical significance and reliability of self-reported smoking status in patients with intracranial aneurysms: a review. Clin Neurol Neurosurg 137:44-49, 2015

18. Dupont SA, Wijdicks EF, Manno EM, Lanzino G, Rabinstein AA: Prediction of angiographic vasospasm after aneurysmal subarachnoid hemorrhage: value of the Hijdra sum scoring system. Neurocrit Care 11:172-176, 2009

19. Etminan N, Beseoglu K, Steiger HJ, Hänggi D: The impact of hypertension and nicotine on the size of ruptured intracranial aneurysms. J Neurol Neurosurg Psychiatry 82:4-7, 2011

20. Fargen KM, Neal D, Rahman M, Hoh BL: The prevalence of patient safety indicators and hospital-acquired conditions in patients with ruptured cerebral aneurysms: establishing standard performance measures using the Nationwide Inpatient Sample database. J Neurosurg 119:1633-1640, 2013

21. Feigin V, Parag V, Lawes CM, Rodgers A, Suh I, Woodward M, et al: Smoking and elevated blood pressure are the most important risk factors for subarachnoid hemorrhage in the Asia-Pacific region: an overview of 26 cohorts involving 306,620 participants. Stroke 36:1360-1365, 2005

22. Feigin VL, Rinkel GJ, Lawes CM, Algra A, Bennett DA, van
Gijn J, et al: Risk factors for subarachnoid hemorrhage: an updated systematic review of epidemiological studies. Stroke 36:2773-2780, 2005

23. Gross BA, Rosalind Lai PM, Frerichs KU, Du R: Treatment modality and vasospasm after aneurysmal subarachnoid hemorrhage. World Neurosurg 82:e725-e730, 2014

24. Ho AL, Lin N, Frerichs KU, Du R: Smoking and intracranial aneurysm morphology. Neurosurgery 77:59-66, 2015

25. Hoh BL, Chi YY, Lawson MF, Mocco J, Barker FG II: Length of stay and total hospital charges of clipping versus coiling for ruptured and unruptured adult cerebral aneurysms in the Nationwide Inpatient Sample database 2002 to 2006. Stroke 41:337-342, 2010

26. Hoh BL, Kleinhenz DT, Chi YY, Mocco J, Barker FG II: Incidence of ventricular shunt placement for hydrocephalus with clipping versus coiling for ruptured and unruptured cerebral aneurysms in the Nationwide Inpatient Sample database: 2002 to 2007. World Neurosurg 76:548-554, 2011

27. Hoh BL, Nathoo S, Chi YY, Mocco J, Barker FG II: Incidence of seizures or epilepsy after clipping or coiling of ruptured and unruptured cerebral aneurysms in the nationwide inpatient sample database: 2002-2007. Neurosurgery 69:644-650, 2011

28. Hoh BL, Rabinov JD, Pryor JC, Carter BS, Barker FG II: Inhospital morbidity and mortality after endovascular treatment of unruptured intracranial aneurysms in the United States, 1996-2000: effect of hospital and physician volume. AJNR Am J Neuroradiol 24:1409-1420, 2003

29. Inagawa T: Risk factors for cerebral vasospasm following aneurysmal subarachnoid hemorrhage: a review of the literature. World Neurosurg 85:56-76, 2016

30. Jaja BN, Saposnik G, Nisenbaum R, Lo BW, Schweizer TA, Thorpe KE, et al: Racial/ethnic differences in inpatient mortality and use of institutional postacute care following subarachnoid hemorrhage. J Neurosurg 119:1627-1632, 2013

31. Jamal A, Agaku IT, O'Connor E, King BA, Kenemer JB, Neff L: Current cigarette smoking among adults-United States, 2005-2013. MMWR Morb Mortal Wkly Rep 63:1108-1112, 2014

32. Juvela $S$ : Cigarette smoking and death following subarachnoid hemorrhage. J Neurosurg 95:551-554, 2001

33. Juvela S, Hillbom M, Numminen H, Koskinen P: Cigarette smoking and alcohol consumption as risk factors for aneurysmal subarachnoid hemorrhage. Stroke 24:639-646, 1993

34. Juvela S, Lehto H: Risk factors for all-cause death after diagnosis of unruptured intracranial aneurysms. Neurology 84:456-463, 2015

35. Khatri R, Tariq N, Vazquez G, Suri MF, Ezzeddine MA, Qureshi AI: Outcomes after nontraumatic subarachnoid hemorrhage at hospitals offering angioplasty for cerebral vasospasm: a national level analysis in the United States. Neurocrit Care 15:34-41, 2011

36. Kim CK, Kim BJ, Ryu WS, Lee SH, Yoon BW: Impact of smoking cessation on the risk of subarachnoid haemorrhage: a nationwide multicentre case control study. J Neurol Neurosurg Psychiatry 83:1100-1103, 2012

37. Krishnamurthy S, Kelleher JP, Lehman EB, Cockroft KM: Effects of tobacco dose and length of exposure on delayed neurological deterioration and overall clinical outcome after aneurysmal subarachnoid hemorrhage. Neurosurgery 61:475-481, 2007

38. Kshettry VR, Rosenbaum BP, Seicean A, Kelly ML, Schiltz NK, Weil RJ: Incidence and risk factors associated with in-hospital venous thromboembolism after aneurysmal subarachnoid hemorrhage. J Clin Neurosci 21:282-286, 2014

39. Lai LT, Morgan MK, Patel NJ: Smoking increases the risk of de novo intracranial aneurysms. World Neurosurg 82:e195e201, 2014

40. Lasner TM, Weil RJ, Riina HA, King JT Jr, Zager EL, Raps 
EC, et al: Cigarette smoking-induced increase in the risk of symptomatic vasospasm after aneurysmal subarachnoid hemorrhage. J Neurosurg 87:381-384, 1997

41. McDonald RJ, Cloft HJ, Kallmes DF: Impact of admission month and hospital teaching status on outcomes in subarachnoid hemorrhage: evidence against the July effect. J Neurosurg 116:157-163, 2012

42. Nuño M, Patil CG, Lyden P, Drazin D: The effect of transfer and hospital volume in subarachnoid hemorrhage patients. Neurocrit Care 17:312-323, 2012

43. Ortiz R, Stefanski M, Rosenwasser R, Veznedaroglu E: Cigarette smoking as a risk factor for recurrence of aneurysms treated by endosaccular occlusion. J Neurosurg 108:672675, 2008

44. Pobereskin LH: Influence of premorbid factors on survival following subarachnoid hemorrhage. J Neurosurg 95:555559,2001

45. Seder DB, Schmidt JM, Badjatia N, Fernandez L, Rincon F, Claassen J, et al: Transdermal nicotine replacement therapy in cigarette smokers with acute subarachnoid hemorrhage. Neurocrit Care 14:77-83, 2011

46. Seicean A, Alan N, Seicean S, Neuhauser D, Selman WR, Bambakidis NC: Risks associated with preoperative anemia and perioperative blood transfusion in open surgery for intracranial aneurysms. J Neurosurg 123:91-100, 2015

47. Siddiq F, Chaudhry SA, Tummala RP, Suri MF, Qureshi AI: Factors and outcomes associated with early and delayed aneurysm treatment in subarachnoid hemorrhage patients in the United States. Neurosurgery 71:670-678, 2012

48. Smith GA, Dagostino P, Maltenfort MG, Dumont AS, Ratliff JK: Geographic variation and regional trends in adoption of endovascular techniques for cerebral aneurysms. J Neurosurg 114:1768-1777, 2011

49. Veeravagu A, Chen YR, Ludwig C, Rincon F, Maltenfort M, Jallo J, et al: Acute lung injury in patients with subarachnoid hemorrhage: a nationwide inpatient sample study. World Neurosurg 82:e235-e241, 2014

50. Washington CW, Derdeyn CP, Dacey RG Jr, Dhar R, Zipfel GJ: Analysis of subarachnoid hemorrhage using the Nationwide Inpatient Sample: the NIS-SAH Severity Score and Outcome Measure. J Neurosurg 121:482-489, 2014

51. Weir BK, Kongable GL, Kassell NF, Schultz JR, Truskowski LL, Sigrest A: Cigarette smoking as a cause of aneurysmal subarachnoid hemorrhage and risk for vasospasm: a report of the Cooperative Aneurysm Study. J Neurosurg 89:405-411, 1998

52. Wiley LK, Shah A, Xu H, Bush WS: ICD-9 tobacco use codes are effective identifiers of smoking status. J Am Med Inform Assoc 20:652-658, 2013

\section{Disclosures}

Dr. Ali Aziz-Sultan reports being a consultant for Covidien and Codman. Dr. Gormley reports being a consultant for Codman.

\section{Author Contributions}

Conception and design: Du, Dasenbrock. Acquisition of data: Dasenbrock, Rudy, Lai. Analysis and interpretation of data: Dasenbrock, Rudy. Drafting the article: Dasenbrock, Rudy. Critically revising the article: Du, Dasenbrock, Smith, Frerichs, Gormley, Aziz-Sultan. Reviewed submitted version of manuscript: Du, Dasenbrock, Smith, Frerichs, Gormley, Aziz-Sultan. Approved the final version of the manuscript on behalf of all authors: Du. Statistical analysis: Dasenbrock. Study supervision: Du.

\section{Correspondence}

Rose Du, Department of Neurosurgery, Brigham and Women's Hospital, 75 Francis St., Boston, MA 02115. email: rdu@bwh. harvard.edu. 